\title{
TECNOLOGIA DE FIBRAS
}

NOTA

\section{MICROFIAÇÃO E FIAÇÃO INDUSTRIAL DE ALGODÃO ${ }^{(1)}$}

\author{
NELSON PAULIERI SABINO ${ }^{(2,3)}$; JULIO ISAO KONDO ${ }^{(2)}$
}

\begin{abstract}
RESUMO
Foram estimados coeficientes de correlação e equações de regressão linear para previsão da tenacidade e alongamento de fios de algodão de título 27 tex, em nível industrial (Y), com base nos resultados dessas mesmas propriedades obtidas de fios produzidos por microfiação $(X)$, do Centro de Algodão e Fibrosas Diversas do Instituto Agronômico (IAC). Os coeficientes de correlação (r) entre os dois processos foram $0,958^{* *}$ e $0,973^{* *}$ para tenacidade e alongamento respectivamente.

Palavras-chave: algodão, microfiação, fiação industrial, fio , fibra.
\end{abstract}

\section{ABSTRACT \\ MINIATURE SPINNING AND INDUSTRIAL SPINNING OF COTTON}

Correlation and regression coefficients were estimated with a 27 tex yarn spun by a miniature spinning equipment $(\mathrm{X})$ and yarn of the same count spun through an industrial plant $(\mathrm{Y})$ using 30 pairs of samples. The correlation coefficients $(r)$ between the two processes were respectively, $0.958^{* *}$ and $0.973^{* *}$ for tenacity and elongation.

Key words: cotton, miniature spinning, industrial spinning, fiber , yarn.

\section{Introdução}

Os testes de fiação em pequenas amostras têm sido utilizados, tanto por melhoristas no julgamento de cultivares de algodoeiro, como por estabelecimentos industriais na determinação da qualidade e grau de fiabilidade de algodões de origens diferentes. Esses testes foram iniciados por W.L. Balls e seus associados, em 1920, e modificados para avaliar materiais genéticos em programas de melhoramento, na Índia, no Egito e no Shirley Institute na Inglaterra (HANCOCK, 1945). Nos Estados Unidos foram utilizados inicialmente pelo Agriculture Marketing Service (AMS), tendo, cada amostra, cerca de $2 \mathrm{~kg}$ a $4 \mathrm{~kg}$ de algodão, passando-se posteriormente aos testes com amostras contendo $50 \mathrm{~g}$ (LANDSTREET et al., 1959).
HANCOCK (1945) verificou que existe forte correlação $\left(r=0,998^{* *}\right)$ entre os testes com pequenas amostras $(60 \mathrm{~g})$ de algodão e os testes normais, com $1 \mathrm{~kg}$, utilizados em Giza, no Egito, para comparar resultados de tenacidade do fio de algodão.

LAZZARINI e SABINO (1972), usando 81 pares de valores de tenacidade do fio de algodão de título 27 tex produzido em microfiação $(X)$ e em fiação semi-industrial $(\mathrm{Y})$, mostraram que entre os dois processos existe uma correlação de $r=0,563^{* *}$ e que a equação de regressão é da forma $Y=611,631+0,486 \mathrm{X}$.

No presente trabalho são apresentados os resultados de estudo comparativo entre a tenacidade e alongamento de fios 27 tex produzidos em microfiação (que processa $42 \mathrm{~g}$ de algodão) e a tenacidade e alongamento de fio do mesmo título, produzido em equipamento industrial têxtil, no qual se empregam

$\left({ }^{1}\right)$ Recebido para publicação em 11 de junho e aceito em 28 de novembro de 1999. Trabalho apresentado no II Congresso Brasileiro de Algodão, Ribeirão Preto (SP), 1999, e agraciado com o título de Honra ao Mérito.

${ }^{2}$ ) Centro de Algodão e Fibrosas Diversas, Instituto Agronômico, Caixa Postal 28, 13001-970 Campinas (SP). E-mail: nsabino@cec.iac.br

(3) Com bolsa de produtividade em pesquisa do CNPq. 
grandes quantidades dessa matéria-prima. Neste último caso, os equipamentos representam os mais modernos processos de formação de fios para confecção de tecidos, operando com grandes velocidades em seus filatórios para obter altos níveis de produtividade.

\section{Material e Métodos}

Foram utilizadas três misturas de algodão provenientes de fardos, correspondendo a três categorias diferentes em termos de qualidade da fibra: superior (A), intermediária (B) e inferior (C). Para a definição de tais categorias foram utilizados os resultados obtidos na determinação das propriedades tecnológicas da fibra, através do Sistema HVI (High Volume Instruments), envolvendo comprimento, uniformidade de comprimento, índice de fibras curtas, tenacidade de ruptura, elongação, índice Micronaire, reflectância e nível de amarelecimento da fibra.

Dez amostras de cada mistura foram processadas em nível industrial, em máquinas Rieter e Ingolstadt, e de cada uma delas foram coletadas $50 \mathrm{~g}$ para processamento na microfiação Shirley, pertencente ao Laboratório de Pesquisa do Centro de Algodão e Fibrosas Diversas do Instituto Agronômico (IAC). Este equipamento é constituído por uma Carda, um Passador e um Filatório, e o processamento é feito pelo método direto de fita a fio.

Para a determinação da tenacidade e alongamento dos fios de título 27 tex com torção $\alpha_{\mathrm{e}}=4,0$ produzidos na microfiação, foi utilizado o dinamômetro DYNAMAT II, da Uster, cujo tempo de realização de cada ruptura é de cerca de 20 segundos. Na indústria utilizou-se o TENSORAPID, da Uster, com duração de cerca de um segundo para cada prova. A tenacidade do fio representa o valor médio da força de ruptura, em gramas, pelo título unitário do fio singelo em Tex, e é denominada RKM. O alongamento de ruptura é dado em porcentagem.

Para as análises de correlação e de regressão simples foram utilizados os resultados dos 30 pares de valores obtidos com as amostras estudadas. Com as análises procurou-se estabelecer as equações para estimar a tenacidade e o alongamento do fio em fiação industrial $(\mathrm{Y})$, a partir dos resultados obtidos na microfiação $(X)$.

\section{Resultados e Discussão}

Os resultados médios da tenacidade e do alongamento dos fios produzidos em fiação industrial e em microfiação das dez amostras de cada mistura, bem como seus respectivos coeficientes de variação, são apresentados no quadro 1.

Os coeficientes de correlação obtidos com fios produzidos em fiação industrial e em microfiação, tanto no caso da tenacidade como de alongamento, apresentaram valores significativos (ao nível de $1 \%$ ), conforme demonstrado no quadro 2. Os resultados indicam um alto grau de associação entre os dados, sendo, portanto, possível estimar (através de equações de regressão) a tenacidade e o alongamento de

Quadro 1. Resultados médios de tenacidade e alongamento dos fios produzidos em fiação industrial e em microfiação, obtidos das dez amostras de cada mistura e seus coeficientes de variação

\begin{tabular}{lrcr}
\hline & \multicolumn{3}{c}{ Misturas } \\
Tipo de Fiação & A & B & C \\
\hline Industrial & & & \\
Tenacidade (RKM) & 16,35 & 15,64 & 12,01 \\
CV(5) & 1,94 & 1,21 & 3,75 \\
Alongamento (\%) & 7,23 & 6,36 & 4,47 \\
CV (\%) & 2,02 & 1,95 & 2,35 \\
Microfiação & & & \\
Tenacidade (RKM) & 14,87 & 14,26 & 11,81 \\
CV (\%) & 2,13 & 2,46 & 2,92 \\
Alongamento (\%) & 7,38 & 6,83 & 5,23 \\
CV (\%) & 2,86 & 1,64 & 4,78 \\
\hline
\end{tabular}

Quadro 2. Coeficientes de correlação e de regressão, calculados para a tenacidade e o alongamento de fios 27 tex, entre resultados obtidos em fiação industrial e microfiação

\begin{tabular}{lccccc}
\hline \multirow{2}{*}{ Qualidade do fio } & \multicolumn{3}{c}{ Coeficientes } & \multicolumn{2}{c}{ Regressão $^{(1)}$} \\
\cline { 2 - 6 } & Correlação (r) & Determinação $\left(\mathrm{r}^{2}\right)$ & Exatidão (d) & (a) & (b) \\
\hline Tenacidade (RKM) & $0,958^{* *}$ & 0,917 & 1,000 & $-3,8678$ & 1,3584 \\
Alongamento (\%) & $0,973^{* *}$ & 0,946 & 0,999 & $-1,8255$ & 1,2103 \\
\hline
\end{tabular}

(1) $\mathrm{Y}=\mathrm{a}+\mathrm{bX}$

** significância ao nível de 1\%. 

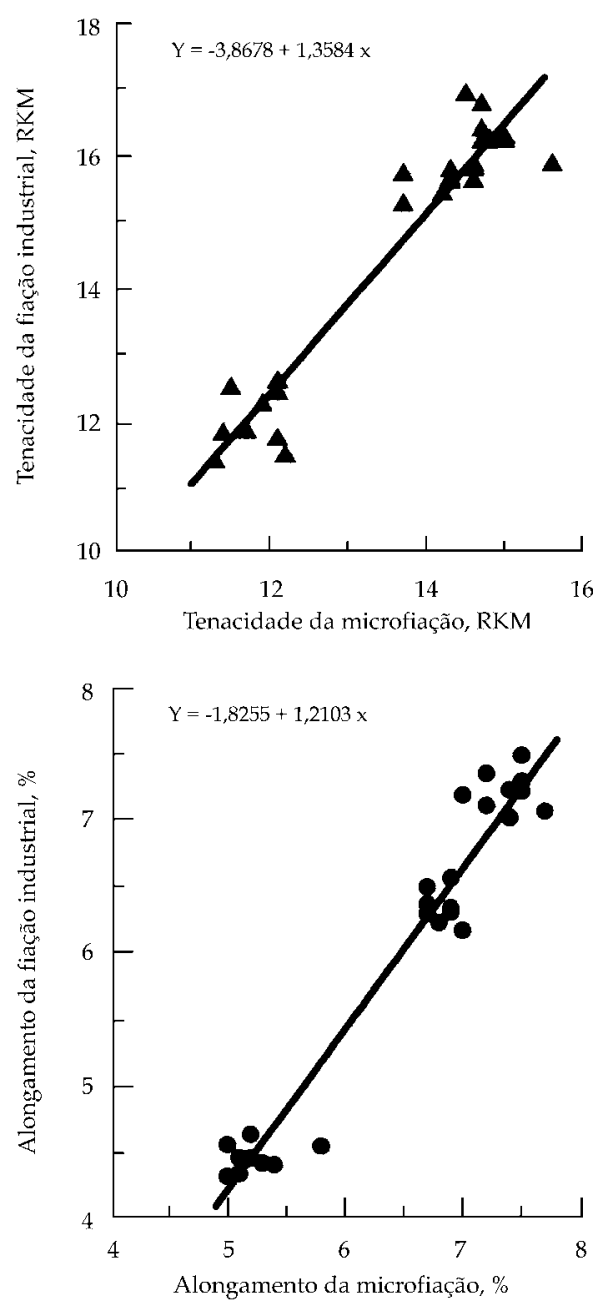

Figura 1. Linhas de regressão dos 30 pares de dados da fiação industrial $(\mathrm{Y})$ e microfiação $(\mathrm{X})$, para as características de Tenacidade (RKM) e Alongamento (\%), dos fios produzidos. fios produzidos em fiação industrial, bem como em fios fornecidos por microfiação.

As equações de regressão para 30 pares de dados com dez amostras de cada mistura de algodão foram: $\mathrm{Y}=-3,8678+1,3584 \mathrm{X}$ para tenacidade dos fios e $Y=-1,8255+1,2103 X$ para alongamento.

Tendo em vista os valores dos coeficientes de determinação apresentados no quadro 2, verifica-se que, para as duas equações, a variação dos resultados da microfiação é recorrente em mais de $90 \%$ das variações nos dados da fiação industrial. A figura 1 mostra as linhas de regressão para os 30 pares de dados relativos à tenacidade e ao alongamento dos fios de algodão.

O fato de se poder estimar a tenacidade e o alongamento de fios de algodão obtidos em fiação industrial - a partir dos resultados obtidos em microfiação - confere maior segurança aos programas de melhoramento do algodoeiro, para a eleição e recomendação de novas cultivares.

\section{Referências Bibliográficas}

HANCOCK, H.A. Uses and accuracy of cotton spinning tests on 60 gram samples. The Journal of the Textile Institute, Manchester, v.36, p.10-18, 1945.

LANDSTREET, C.B., EWALD, P.R.; KERR, T.A. A miniature spinning test for cotton. Textile Research Journal, Princeton, v.29, p.699-706, 1959.

LAZZARINI, J.F.; SABINO, N.P. Estudo comparativo de resistência do fio de algodão em fiação piloto e em fiação industrial. Bragantia, Campinas, v.31, n.1, p.137144, 1972. 